\title{
Effects of Ammonium Polyphosphate/Melamine Additions on Mechanical, Thermal and Burning Properties of Rigid Polyurethane Foams
}

\begin{abstract}
R. YURTSEVEN*
Pamukkale University, Engineering Faculty, Mechanical Engineering Department, Denizli, Turkey

Rigid polyurethane foams are widely used as thermal insulation materials. However, the foams have fairly poor fire performance. Therefore, different flame retardants are used to enhance the fire resistance of the foams. Meanwhile, it should be pointed out that flame retardant additions into the foams may deteriorate the thermal and mechanical properties of the foams. In this study, intumescent flame retardants are synthesized by using ammonium polyphosphate/melamine in different ratios, namely $3 / 1,2 / 1$ and $1 / 1$. The flame retardants were added into the rigid polyurethane foams in $10 \mathrm{wt} \%$. The thermal conductivity, compressive strength, thermogravimetric analysis and UL 94 burning characteristics of the foams were determined and compared. As a result of the experiments, it was found that the best fire resistance can be satisfied with ammonium polyphosphate/melamine (3/1) addition. However, there were slightly increasing in thermal conductivity and decreasing in compressive strength of the foam.
\end{abstract}

DOI: 10.12693/APhysPolA.135.775

PACS/topics: rigid polyurethane, ammonium polyphosphate, melamine, mechanical, thermal, burning

\section{Introduction}

Polyurethane materials have recently begun to be used more and more because of the advantages of their production methods and their superior mechanical and thermal properties $[1,2]$. They can be produced as thermoset (rigid foam, flexible foam) and thermoplastic material according to the places of use. Among them, flexible polyurethane foams (PUF) are used in automotive and furniture sectors, while rigid polyurethane foams (PUR) are used in heat insulation sector due to their low thermal conductivity coefficients. PUR materials are also preferred for vehicle insulations due to their low densities and adequate strength values [2].

The addition of different fillers and additives has also become important in order to improve the thermal behavior and mechanical properties of polyurethane materials [3]. A wide variety of metallic and mineral fillers are used to improve properties of PUR material and obtain more economical products. Depending on the chemical composition and particle size of the fillers, the thermal, burning and mechanical properties of the PUR foams are positively or negatively affected [3].

Intumescent flame retardants (IFR) are used in polymers to produce flame resistant materials [4]. Meanwhile, it should be pointed out that flame retardant additions into the foams may deteriorate the mechanical properties of the foams. In general, IFR are synthesized by using an inorganic acid source and a carbonization agent. Different chemical materials are used as carbonization agent. Ammonium polyphosphate (APP) is widely used

*e-mail: ryurtseven@pau.edu.tr chemical material as intumescent flame retardants in PUR materials [5]. In order to improve the flame retardant performance of APP, work on different materials is ongoing $[3-5]$.

In this study, intumescent flame retardants (IFR) are synthesized by using ammonium polyphosphate $(\mathrm{APP}) /$ melamine (MEL) in different ratios, namely $3 / 1$, $2 / 1$ and $1 / 1$. Melamine was used as foaming agent. The aim of this work is to determine the best APP/MEL ratio in IFR. The flame retardants were added into the rigid polyurethane foams in $10 \mathrm{wt} \%$.

\section{Experimental procedure}

\subsection{Materials}

Two main components of the rigid polyurethane foams (polyol and isocyanate) were purchased from TEKPOL (Technical Polyurethane Ltd-Turkey). For flame retardant system; ammonium polyphosphate (APP), (Exolit AP $423, n>1000$, phase II) was kindly supplied by Clariant Company from Turkey. Melamine (MEL) was kindly supplied by DSM company from Netherlands. In Table I, the formulations of the samples and the density values of the samples are given.

Formulations of PUR (138 g polyol, $162 \mathrm{~g}$

TABLE I isocyanate, $50 \mathrm{~kg} / \mathrm{m}^{3}$ ) foam samples.

\begin{tabular}{c|c|c}
\hline \hline \multirow{2}{*}{ Sample } & APP & MEL \\
\cline { 2 - 3 } & \multicolumn{2}{|c|}{ IFR $n(30 \mathrm{~g})$} \\
\hline neat PUR & - & - \\
$10 \%$ IFR 1 & $22.5 \mathrm{~g}$ & $7.5 \mathrm{~g}$ \\
$10 \%$ IFR 2 & $20 \mathrm{~g}$ & $10 \mathrm{~g}$ \\
$10 \%$ IFR 3 & $15 \mathrm{~g}$ & $15 \mathrm{~g}$
\end{tabular}




\subsection{Sample preparation and test procedure}

Polyurethane materials mainly consist of polyol and isocyanate which are in liquid form. The additives were homogenized by adding into the polyol. The polyol and isocyanate were mixed with a mechanical stirrer for 20 seconds at $2000 \mathrm{rpm}$ in a cup. The prepared mixture was poured into aluminum mold heated in the press until the reaction is completed. After the polymerization reaction is completed, the samples were prepared by cutting in accordance with standards. The samples kept in a climate chamber set to $23^{\circ} \mathrm{C} \pm 2{ }^{\circ} \mathrm{C}$ temperature and $50 \pm 5 \%$ relative humidity conditions for at least 24 hours before the experiments.

Compression tests were carried out according to the relevant ASTM D 1621-10 standards. The sizes of samples used in the tests are $50 \mathrm{~mm} \times 50 \mathrm{~mm} \times 50 \mathrm{~mm}$. Compression in the tests was carried out at a rate of $2.5 \mathrm{~mm} / \mathrm{min}$ in the direction of expansion of the foam material. During the tests, the compression process was continued until $13 \%$ of the original thicknesses of the sample was deformed.

Determination of the thermal conductivity coefficient was carried out with the Kyoto Electronics QTM-500 heat transfer coefficient meter. As a measurement method, hot wire method is used (ASTM C1113M). With UL-94 burning test, burning behavior of materials and flame propagation speed were found. The samples were cut in sizes of $150 \mathrm{~mm} \times 50 \mathrm{~mm} \times 10 \mathrm{~mm}$. TGA analysis measures the amount of weight change of a material depending on the temperature. Perkin-Elmer Diamond thermogravimetric analysis equipment was used at a rate of $20^{\circ} \mathrm{C} / \mathrm{min}$ under nitrogen between $40^{\circ} \mathrm{C}$ and $800^{\circ} \mathrm{C}$.

\section{Results and discussion}

Effects of $10 \%$ IFR $1(\mathrm{APP} / \mathrm{MEL}=3 / 1)$, IFR 2 $(\mathrm{APP} / \mathrm{MEL}=2 / 1)$ and IFR $3(\mathrm{APP} / \mathrm{MEL}=1 / 1)$ on the compressive strengths of the rigid foams were investigated and the results are shown in Fig. 1.

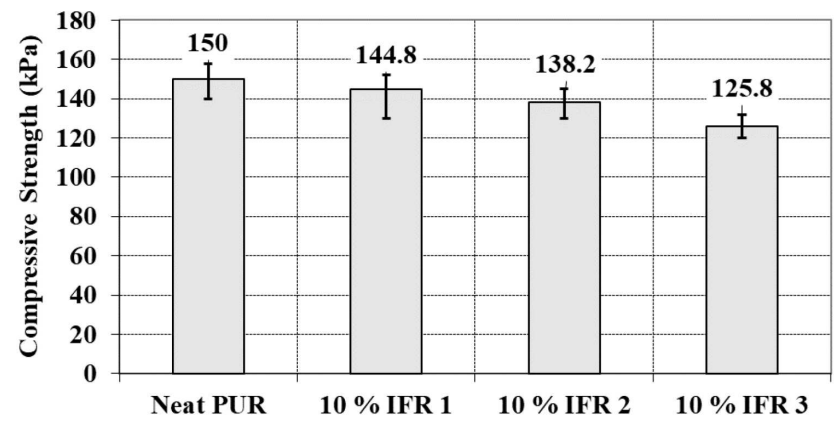

Fig. 1. Effects of IFR additions on the compressive strength.

It was determined that IFR additions resulted in decreasing of the compressive strength and the reduction increased with increasing of MEL in IFR. In other words, the addition of $10 \%$ IFR 1 resulted in a minimal reduction in the compressive strength of the composite foam.
Although IFR 1 addition caused $3.5 \%$ reduction in the compressive strength, IFR 3 addition decreased the compressive strength in $16 \%$. The deterioration of mechanical properties with additives is mentioned in some studies in the literature [2, 5-7]. Mechanical properties are generally dependent on density and cellular structure [8]. In this study, composite foams were produced in closed mold to keep the densities equal. This reduction can be explained by the deterioration of the polymeric and cellular structure.

The thermal conductivity coefficients of PUR foams slightly increased with the intumescent flame retardant additions (Fig. 2). It was determined that $10 \%$ IFR 2 addition resulted in maximum increasing $(5 \%)$ in the thermal conductivity coefficient of the foam. IFR 1 addition caused $3.2 \%$ increasing in the thermal conductivity coefficient. The main reasons for the increase of thermal conductivity coefficient are the increase in density, the decrease in the closed cell ratio. With the addition of IFR, the viscosity of the polymer mixture increases, so that the ratio of open cells increases $[9,10]$.

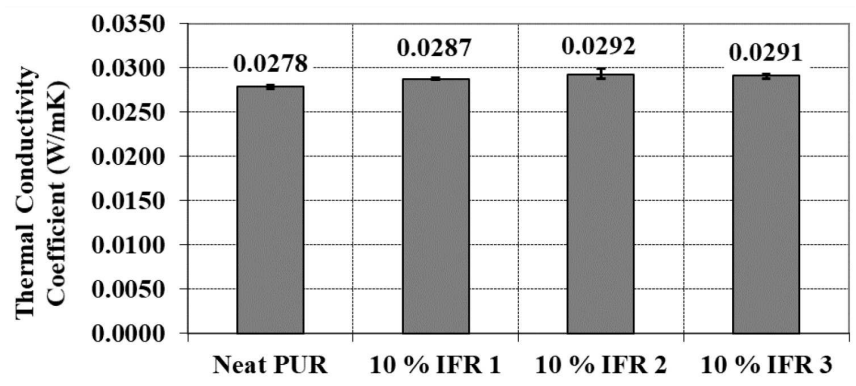

Fig. 2. Effects of IFR additions on thermal conductivity coefficient.

$\mathrm{APP}+\mathrm{MEL}$ has shown that it is a useful intumescent flame retardant formulation with a good synergistic effect (Fig. 3). MEL uses a quantity of heat energy generated during combustion to produce non-flammable nitrogen-containing vapor products. These vapors also

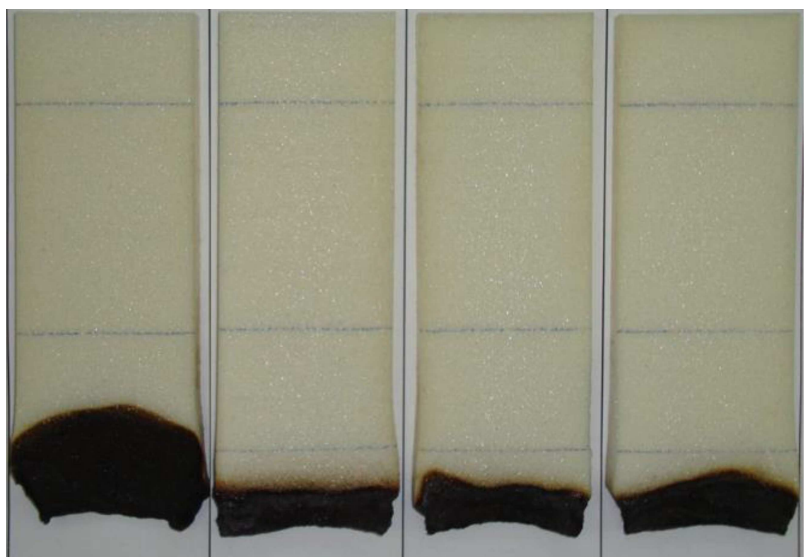

Neat PUR $\quad 10 \%$ IFR $110 \%$ IFR $210 \%$ IFR 3

Fig. 3. UL-94 Burning test results. 
dilute the flammable gas species [11]. However, it has been observed that it has a negative effect on the carbonized layer formed in increasing MEL ratios in the IFR. UL 94 burning tests of the composite foams showed that the best fire resistance appeared with $10 \%$ IFR 1 (APP/MEL:3/1) addition.

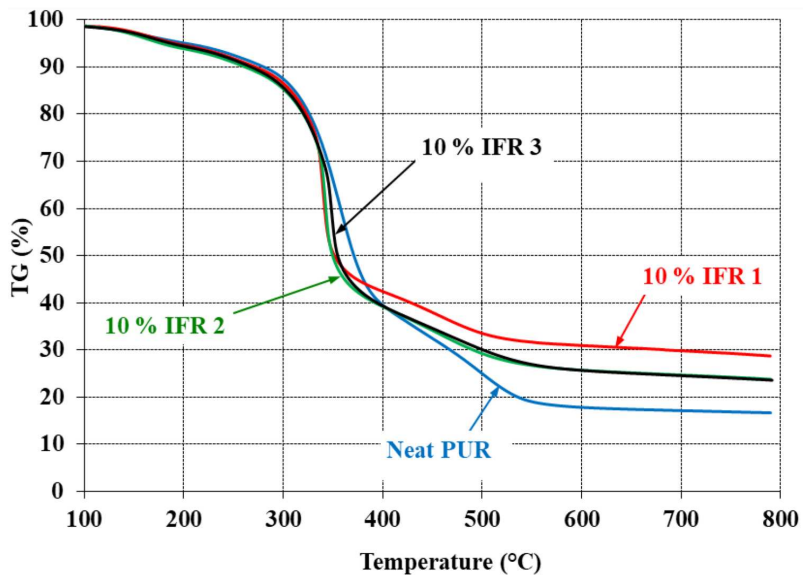

Fig. 4. TG curves of all samples.

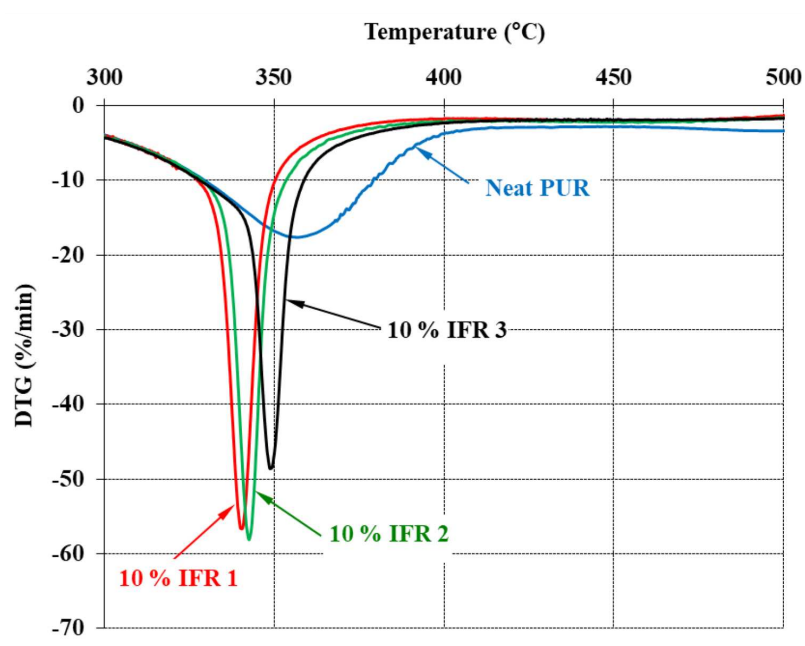

Fig. 5. DTG curves of all samples.

The results of thermogravimetric analysis shown in Figs. 4 and 5 are suited with the results of the UL94 burning test. The fastest decomposition in the neat PUR sample was found at $354.7^{\circ} \mathrm{C}$, while the IFR 1 added sample was detected at $341.7^{\circ} \mathrm{C}$. (Fig. 5). The amount of mass remaining at $700^{\circ} \mathrm{C}$ in the neat PUR sample was measured as $17.1 \%$ (Fig. 4). The thermal degradation rates of PUR materials with IFR additions are very fast. However, this rapid thermal decomposition is then rapidly decelerating. In the case of rapid decomposition of IFR-added samples, an intumescent flame retardant char layer is formed at these moments [7, 10-11]. The highest amount of residual mass $(28.6 \%)$ was obtained in PUR material with IFR 1 addition.

\section{Conclusion}

In this study, the experimental results showed that addition of $10 \%$ the intumescent flame retardant system including ammonium polyphosphate and melamine (IFR 1APP/MEL:3/1) significantly enhanced the fire resistance and thermal degradation of the rigid polyurethane foam. Although, the compression strength decreased approximately $3.5 \%$ with the addition of $10 \%$ IFR 1 , the absolute value, which is $148.8 \mathrm{kPa}$, is acceptable value for many applications. Meanwhile, $10 \%$ IFR 1 caused $3.2 \%$ increases in the thermal conductivity of the foam, but it may be compensated with slightly increasing the thickness of the insulation. As a result, IFR 1 as a nonhalogen flame retardant can be preferred for the rigid polyurethane foams.

\section{Acknowledgments}

I would like to thank the Pamukkale University Scientific Research Council (BAP) for supporting this study. Since the some of the equipment and materials were provided with the support of TUBITAK (The Scientific and Technological Research Council of Turkey) under project contract no. 108T246, the author would like to thank TUBITAK.

\section{References}

[1] I. Zarzyka, J. Appl. Polym. Sci. 135, 45748 (2018).

[2] M. Yazıc1, Acta Phys. Pol. A 129, 613 (2016).

[3] Y.Liu, J. He, R.Yang, J Mater Sci. 52, 4700 (2017).

[4] N. Usta, Journal of Applied Polymer Science 124, 3372 (2012).

[5] J. Czech-Polak, R. Oliwa, M. Oleksy, G. Budzik, Polimery 63, 115 (2018).

[6] R. Yurtseven, A.R. Tarakcılar, M. Topçu, Journal of the Faculty of Engineering and Architecture of Gazi University 28, 841 (2013).

[7] C. Wang, Y. Wu, Y. Li, Q. Shao, X. Yan, C. Han, Z. Wang, Z. Liu, Z Guo, Polym Adv Technol. 29, 668 (2018).

[8] H.K Peng, X.X. Wang, T.T Li, S.Y. Huang, Q. Lin, B.C. Shiu, C.W. Lou, RSC Adv. 8, 33542 (2018).

[9] S. Michałowski, K. Pielichowski, Journal of Thermal Analysis and Calorimetry 134, 1351 (2018).

[10] M. Thirumal, D. Khastgir, G.B. Nando, Y.P. Naik, N.K. Singha, Polymer Degradation and Stability 95, 1138 (2010).

[11] D.K. Chattopadhyay, D.C. Webster, Progress in Polymer Science 34, 1068 (2009). 